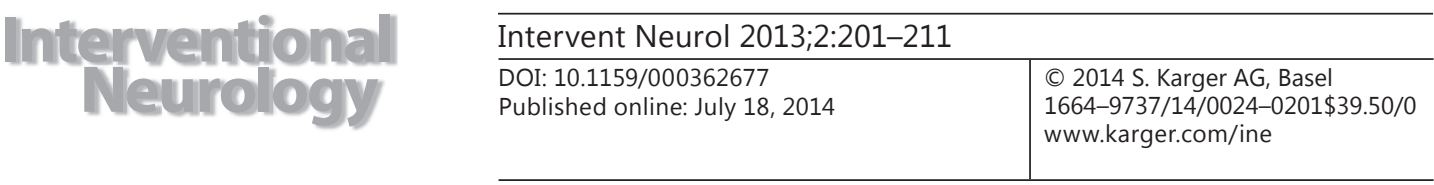

\title{
Review
}

\section{Hyperbaric Oxygen Therapy in Acute Ischemic Stroke: A Review}

\author{
Zheng Ding $^{a} \quad$ Wesley C. Tong ${ }^{b}$ Xiao-Xin Lu ${ }^{a}$ Hui-Ping Peng ${ }^{a}$ \\ a Department of Hyperbaric Oxygen, Fuzhou General Hospital of Nanjing Command, PLA, \\ Fuzhou, and ${ }^{b}$ Department of Rehabilitation Medicine, Huashan Hospital, Fudan University, \\ Shanghai, China
}

\section{Key Words}

Hyperbaric oxygen - Brain ischemia - Molecular mechanisms - Early medical intervention . Neuroprotective effects

\begin{abstract}
Stroke, also known as cerebrovascular disease, is a common and serious neurological disease, which is also the fourth leading cause of death in the United States so far. Hyperbaric medicine, as an emerging interdisciplinary subject, has been applied in the treatment of cerebral vascular diseases since the 1960s. Now it is widely used to treat a variety of clinical disorders, especially hypoxia-induced disorders. However, owing to the complex mechanisms of hyperbaric oxygen ( $\mathrm{HBO}$ ) treatment, the therapeutic time window and the undefined dose as well as some common clinical side effects (such as middle ear barotrauma), the widespread promotion and application of HBO was hindered, slowing down the hyperbaric medicine development. In August 2013, the US Food and Drug Administration declared artery occlusion as one of the 13 specific indications for HBO therapy. This provides opportunities, to some extent, for the further development of hyperbaric medicine. Currently, the mechanisms of HBO therapy for ischemic stroke are still not very clear. This review focuses on the potential mechanisms of HBO therapy in acute ischemic stroke as well as the time window.
\end{abstract}

(C) 2014 S. Karger AG, Basel

\section{Introduction}

Stroke is the fourth leading cause of death in the United States. One in 6 people worldwide will have a stroke during their lifetime and one third of the survivors will experience a recurrence [1-3]. In the past 4 decades, the incidence rates of stroke decreased by $42 \%$ in the economically developed nations, while they increased in the developing countries [4]. Stroke contributes 
to a series of complications, such as motor and cognitive deficits [5], aphasia [6], dysphagia [7] and some psychological disorders [8], which aggravate the patient's family and socioeconomic burden [9]. A recent study reported that the total direct and indirect costs of cardiovascular disease and stroke have been estimated to be USD 297.7 billion in the United States [10]. Actually, due to the uncertainty and unpredictability of indirect losses, they are lower than the real data. Of course, the stroke rate in China shows regional differences [11]. Cerebrovascular diseases can be divided into hemorrhagic stroke and ischemic stroke, and approximately $80 \%$ of them are ischemic brain injury [12]. Acute ischemic stroke (AIS), characterized by an occlusion of the cerebral artery, is the major cause of high morbidity and mortality in the aging population worldwide [13]. However, the therapeutic strategies for AIS are, to a large extent, still limited. Recombinant tissue plasminogen activator is the only therapeutic drug for AIS approved by the US Food and Drug Administration [14]. Only 2-5\% of the patients [15] who experienced acute ischemic brain injury have received thrombolytic treatment, mainly due to the limited time window of thrombolysis, bleeding complications, or high costs. Accordingly, seeking a comprehensive multidisciplinary treatment for AIS is indispensable.

To date, no optimal neuroprotective agent for the clinical treatment of AIS has been developed yet. Hyperbaric oxygen (HBO) is a nondrug and noninvasive treatment, in some cases applied as the primary treatment modality, which has been widely used in clinical practice for many diseases and has led to satisfactory outcomes, especially in the areas of acute carbon monoxide poisoning [16], gas gangrene [17] and decompression sickness [18]. Lee et al. [19] observed that the annually published number of HBO therapy papers has gradually increased during the past decade. In addition, stroke, carbon monoxide poisoning, radiation injury and wounds formed a major area of HBO research. Numerous studies have demonstrated that HBO treatment is capable of increasing oxygen supply, ameliorating cerebral circulation, reducing ischemia-reperfusion injury and alleviating the extent of irreversible neurological impairment. Interestingly, a recently randomized, prospective trial [20] has shown that HBO therapy can activate the neuroplasticity of brain tissues in post-stroke patients, even in the chronic phase. This provides a brilliant prospect for the further in-depth study of HBO. At present, HBO treatment for cerebral infarction has been applied for several decades. However, current studies are still based on animal experiments, and there are few randomized controlled trials in the literature. Actually, 6 randomized controlled trials involving 283 participants updated the former summary by Bennett et al. [21]. This review focuses on the underlying molecular mechanisms of HBO therapy in acute ischemic stroke, and the therapeutic time window will also be mentioned.

\section{Basic Physiological Effects of HBO Therapy}

HBO therapy is a treatment in which the patient breathes $100 \%$ oxygen while being exposed to increased atmospheric pressure [22,23]. Ischemic stroke immediately contributes to the reduction of regional cerebral blood flow as well as the deficiency of brain tissue oxygen supply. Compared with other organs, brain tissue is the most vulnerable to hypoxia with low antioxidant defenses. If not promptly treated, serious outcomes will follow. The primary therapeutic goal for acute stroke, therefore, is to restore or ameliorate the reperfusion of the ischemic core and penumbra. HBO treatment has long been proposed as a commonly available therapeutic schedule to ameliorate AIS-induced brain tissue hypoxia [24]. Previous studies have demonstrated that HBO therapy can enhance the arterial partial pressure of oxygen $\left(\mathrm{PaO}_{2}\right)$ [25], increase the oxygen content [26], stabilize the blood-brain barrier [27], decrease the intracranial pressure and relieve cerebral edema [27, 28]. Some clinical studies $[29,30]$ have justified that intravenous thrombolysis with alteplase, 3-4.5 h after the onset of AIS, may 
be effective for clinical outcomes. Few people actually received thrombolytic therapy since the safety and efficacy of thrombolysis, to some extent, is also elusive. Meanwhile, with the continuous development of medical technology, newer diagnostic techniques and therapeutic strategies have emerged in clinical stem cell transplantation, such as anticoagulation and antiplatelet interventions. It is worth mentioning that HBO is a relatively safe therapeutic method and holds great promise [31].

\section{Effects of HBO on Oxidative Stress}

The pathogenesis of AIS is highly complex and involves multiple mechanisms including excitotoxicity, acid toxicity, ionic imbalance, oxidative and nitrosative stress, inflammation and apoptosis [32]. Increasing evidence suggests that oxidative stress is considered to be one of the most important contributing factors causing cerebral ischemia-reperfusion injury. Oxidative stress leads to excessive production of free radicals, directly or indirectly triggering necrosis and apoptosis. From the perspective of molecular mechanisms, cerebral ischemic stroke initiates a series of connected events, involving the generation of reactive oxygen species (ROS) and reactive nitrogen species [33]. Prolonged hypoxia eventually contributes to the oxidation and antioxidant system imbalance and tissue injuries. In animal models, HBO preconditioning (2.5 ATA, $1 \mathrm{~h}, 2$ days) reduces the ischemia-reperfusion injury of the middle cerebral artery occlusion (MCAO) via increasing the expression of antioxidant enzymes [34]. Appropriate HBO therapy can effectively alleviate oxidative stress [35]. Nevertheless, HBO also increases the generation of ROS and reactive nitrogen species [36]. Large doses or a longterm schedule of HBO therapy may exacerbate peroxidation injury of ischemic penumbra and destroy the integrity of the blood-brain barrier.

ROS contains many species, such as hydrogen peroxide $\left(\mathrm{H}_{2} \mathrm{O}_{2}\right)$, hydroxyl radical $\left(\mathrm{OH}^{-}\right)$, and superoxide $\left(\mathrm{O}_{2}^{-}\right)$[37]. Although many of the ROS may contribute to cytotoxicity, it is generally considered that hydroxyl free radicals are one of the most active and toxic matters associated with killing erythrocytes, and deteriorating cell membranes and deoxyribonucleic acid as well as polysaccharide compounds. They are mainly responsible for irreversible cell injury and lethal effects [38]. Yang et al. [39] using HBO therapy (2.8 ATA, $1 \mathrm{~h}$ ) for MCAO rats indicate that $\mathrm{HBO}$ can dramatically reduce the formation of hydroxyl free radicals in the striatum. However, longer duration of HBO treatment may upregulate the expression of oxidase in permanent ischemic stroke models [40]. The specific mechanisms of HBO therapy on oxidative stress remain to be proven. Currently, in mechanism and efficacy research of HBO, the common indicators include superoxide dismutase (SOD), glutathione peroxidase (GSH-px), catalase, lipid peroxidation, and malondialdehyde, and SOD and GSH-px, as free radical scavengers, are the main antioxidant enzymes. The activity of SOD and GSH-px can reflect the body's ability to eliminate oxygen free radicals. Malondialdehyde is the product of lipid peroxidation, which indirectly reflects the severity of ischemic tissues attacked by free radicals. A large number of studies have proven that early HBO treatment is able to significantly ameliorate the conditions of ischemic core and penumbra, associated with the enhancement of SOD and catalase activity as well as the reduction of malondialdehyde and lipid peroxidation levels [34, 41, 42]; however, GSH-px shows insignificant changes [34, 41]. These studies proved that HBO plays a critical role in the antioxidant procedure by activating endogenous antioxidant enzyme activity. In addition, excessive duration of the treatment and dose will have opposite effects.

In recent years, the effects of nitrogen monoxide (NO) on cerebral ischemia-reperfusion injury attracted the investigators' attention. NO, a neurotransmitter of the central nervous system, plays an essential role in regulating the cerebral vascular tone, participating in cell 
information transfer among others. It is a gaseous molecule produced by NO synthase (NOS) involving neuronal NOS, inducible/inflammatory NOS (iNOS), and endothelial NOS (eNOS) [36]. NOS needs oxygen and L-arginine to produce NO [35], while in the condition of ischemic stroke both of them increased. A growing number of studies show that NO plays a dual role in the function of neuroprotection and neurotoxicity for the nervous system [43]. Baynosa et al. [44] found that the effects of HBO (2.5 ATA) on ischemia-reperfusion injury may be related to a series of transduction cascades, an early increase in eNOS enzymatic activity followed by a late-phase increase in eNOS protein expression within the pulmonary tissues. Zhou et al. [45] studied the acute cerebral injury models with HBO therapy and found that HBO might have a positive effect on the central nervous system by influencing the expression of neuronal NOS mRNA/iNOS mRNA. These studies indicate a possible mechanism of HBO therapy to suppress oxidative stress by inhibiting the activity of NOS. However, whether there is an interaction between the activation of eNOS and iNOS is unclear. Further studies need to illuminate the specific pathways that HBO exert on the expression of NOS and NO.

\section{HBO Alleviates Inflammation}

Neuroinflammation is an endogenous protective mechanism associated with neutralization of an insult and restoration of the normal structure and function of the brain [46]. It is generally beneficial to an organism [47]. Inflammatory reaction induced by leukocyte infiltration plays a critical role in the development and progression of ischemic injury. The protective mechanisms of inflammation after brain injury are reflected by the following two aspects: leukocytes inhibit the proliferation and spread of invading pathogens; immune cells generate a variety of neurotrophic factors and promote nervous tissue repair and survival. However, neuroinflammation is usually too severe for self-termination. Therefore, inflammation is the therapeutic objective in stroke [48]. Comprehensive and timely treatment for brain ischemia is essential [49].

Rink et al. [24] found that HBO can significantly decrease the infarct volume during the ischemia-reperfusion of AIS, which is calculated by histological determinations. The main mechanism is to limit leukocyte accumulation of the ischemic-hypoxic area by reducing the reaction of inflammatory chemokine. Unfortunately, the outcomes turned out to be detrimental for identical treatment immediately after reperfusion. Opposite results were also found in some previous experiments for several hours after ischemia-reperfusion by using HBO therapy [50, 51]. Recently, a new study [52] has testified that HBO might attenuate inflammation in transient MCAO rats with a long-course schedule (3 weeks or 2 days after MCAO, repeated for 3 weeks). This point has also been reflected in the HBO therapy of traumatic brain injury [53].

Simultaneously, myeloperoxidase (MPO), a key inflammatory enzyme, is a sign of function and activity of neutrophil granulocytes. MPO is usually used as a biomarker to identify leukocyte levels in ischemic injury and indirectly reflects the effect of HBO on inflammatory response. Breckwoldt et al. [54] has demonstrated that MPO is widely distributed in the ischemic penumbra and positively correlated with infarct size. It can be detected even 3 weeks following ischemic stroke. Miljkovic-Lolic et al. [55] found that HBO therapy is associated with reduced MPO activity and inhibition of neutrophil infiltration. Cyclooxygenase (COX) has two different cyclooxygenase genes including COX-1 and COX-2. In physiological conditions, COX-1 is persistently expressed. COX-2 is inducible to produce inflamed cells such as endotoxin, mitogen and cytokines [56], which is an important element of post-ischemic neuroinflammation. Recent studies $[57,58]$ have shown that the mechanism of HBO to alleviate inflammation may be through inhibiting the COX-2 signaling pathway. 
Matrix metalloproteinases (MMPs) is a family of enzymes that participate in both physiological and pathological tissue remodeling. Romanic et al. [59] demonstrated that brain ischemia contributes to the overexpression of MMP-9, which may give rise to secondary brain injury such as apoptosis, brain edema, hemorrhage, and blood-brain barrier damage. Ostrowski et al. [60] found that HBO therapy can reduce brain MMP-9 activity, tissue expression as well as cell death in global brain ischemia. The same result is shown in traumatic brain injury [61]. Noteworthy, Zhang and Gould [62] further detected that HBO promotes endogenous antioxidants to establish a dynamic balance of the oxidant and antioxidants system via activating the ROS/MAPK/MMP signaling axis in ischemic wounds. Although the anti-inflammatory mechanisms of HBO are undefined, the conclusion may be roughly drawn that HBO comes into effect by a series of cascade reactions, involving the inhibition of MMP-9 activity.

\section{HBO Inhibits Apoptosis and Neuroprotective Effects}

It is well known that mitochondria are the control center of cellular activities. However, they are not only the center of cellular respiratory chain and oxidative phosphorylation, but also play an irreplaceable role in neuronal apoptosis and necrosis. Apoptosis is a major pattern of neuronal cell death in ischemic penumbra [63]. Broughton et al. [64] reviewed the papers and summarized that the signaling pathways of apoptosis are diverse; the mitochondrial pathway is one of the most important way by releasing cytochrome $\mathrm{c}$ as well as stimulating caspase-3. Li et al. [65] showed that HBO preconditioning can reduce cytochrome $\mathrm{c}$ in the hippocampus and ischemic penumbra analyzed by Western blot in an MCAO model. Simultaneously, several studies $[66,67]$ have shown that HBO therapy inhibits the expression of caspase-3 in the cortex and hippocampus of an ischemic model. Lou et al. [68] found that a mitochondrial ATP-sensitive potassium channel has an effect on the anti-apoptotic procedure with early HBO therapy. Additionally, heat shock protein 70 may also be a significant antiapoptosis mechanism of HBO therapy [69].

Hypoxia-inducible factor- $1 \alpha$ (HIF-1 $\alpha$ ), a transcription factor, is one of the principal mediators of homeostasis in human tissues exposed to hypoxia [70]. HIF-1 $\alpha$ has a dual function [71]. During the hypoxic-ischemic period, HIF-1 $\alpha$ has neuroprotective and neurotoxic effects. HIF- $1 \alpha$ comes into effect through the following ways. (1) HIF- $1 \alpha$ administrates the transcription of erythropoietin, which has an anti-apoptotic effect. (2) HIF-1 $\alpha$ promotes the neovascularization by stimulating the expression of vascular endothelial growth factor. However, the neurotoxic effect of HIF- $1 \alpha$ reflects on the reinforcing expression of tumor suppressor genes, such as p53 protein. HIF- $1 \alpha$ also increases the permeability of the bloodbrain barrier in AIS, contributing to the exacerbation of brain edema. Therefore, we could not rashly come to the conclusion that increased HIF-1 $\alpha$ is beneficial or detrimental to our body. Several basic researches [72-74] suggest that HBO significantly reduces the expression of HIF- $1 \alpha$ and its downstream effector proteins and suppresses apoptosis.

At present, neuroprotective agents for ischemic stroke are various, such as radical scavengers, excitatory amino acid (EAA) receptor antagonists, aspirin, and erythropoietin. The molecular pathways and therapeutic targets of neuroprotective agents correspond. These agents have proven to be effective to some extent. However, the utility still remains to be further verified. The neuroprotective mechanisms of $\mathrm{HBO}$ are extremely complex. Considering previous studies, the effects of $\mathrm{HBO}$ on neurological function can be roughly summarized as follows.

Firstly, HBO increases the expression of brain-derived neurotrophic factor (BDNF), glialderived neurotrophic factor (GDNF) and nerve growth factor (NGF), which can nourish the cranial nerve, and promote the proliferation and restoration of the neurons. Numerous 
studies have shown that HBO significantly improves the levels of BDNF, GDNF and NGF in ischemic injury. Simultaneously, studies have shown that the positive effects still exist in brain damage [75] and spinal cord injury [76]. Long-course and repeated HBO therapy for cerebral ischemia can also generate similar outcomes [52, 77].

Secondly, HBO promotes the mobilization and migration of pluripotent mesenchymal stem cells. Regenerative medicine has been a 'hot topic' in recent years, especially regarding stem cell research. A recent study suggests that under the condition of HBO, bone marrow stromal cells increased, which is related to the regulatory factor of Wnt $3 \alpha$ [78]. Bone marrow stem cells are a kind of adult stem cells, which have the capacity of self-replication and multiple differentiation. Previous studies proved that bone marrow stem cells have the ability to secrete GDNF, BDNF and NGF, and play a role in anti-inflammatory, anti-apoptotic, as well as host immune response [79, 80]. Lee et al. [52] have shown that HBO therapy is more likely to promote the mobilization and migration of bone marrow stem cells in MCAO rats via CD34-DAPI double staining.

Thirdly, HBO stimulates the proliferation of astrocytes and inhibits the secretion of microglial cells. Astrocytes, an important component of the central nervous system, play significant roles in nourishing and supporting neurons, repairing injury, and participating immune response [81]. Microglial cells are associated with oxidative stress and secretion of inflammatory cells, which will produce neurotoxicity in the overabundant conditions [82]. An increasing number of studies [83-86] indicated that the attenuation of microglial cells and proliferation of astrocytes are closely linked to HBO therapy.

Fourthly, as is known to us that motor and cognitive functions are indispensable abilities of the human body, ischemic stroke results in varying degrees of motor and cognitive disorders, which aggravates the patient's family and socioeconomic burden. Currently, the principal method of assessment of the motor and cognitive functions for post-ischemic stroke is evaluation forms, such as the National Institutes of Health Stroke Scale, Montreal Cognitive Assessment, Fugl-Meyer Assessment Scale, and Modified Barthel Index. HBO can effectively improve the function of movement and cognition, which reflects on a prospective single-blind controlled trial [87], as well as a case report of acute carbon monoxide poisoning [88]. In addition, HBO combined with acupuncture or modern rehabilitation techniques may generate more favorable outcomes for neurological and motor function [89], which deserved to be investigated for further study. However, HBO therapy is not applicable to all neurological diseases, which seems to be ineffective in children with cerebral palsy [90].

Noteworthy, a recent study [91] proved that autophagy is associated with the neuroprotective effect of ischemia-reperfusion injury. HBO preconditioning gives rise to the alleviation of ischemia-reperfusion injury via stimulating autophagy [65], while the opposite outcome appears in traumatic brain injury [92]. To sum up, the neuroprotective mechanism of HBO is still elusive and therefore worthy of further study.

\section{HBO Modulates Cerebral Blood Flow and Brain Metabolism}

The therapeutic strategy for AIS is aimed to restore cerebral blood flow and minimize the detrimental effects of ischemia on neurons [93]. Previous studies have focused on the effects of HBO on cerebral blood flow, although hyperoxia is associated with the suppression of brain metabolic rate and cerebral blood flow in normal people [94]. Accumulating evidence implicates that HBO therapy significantly ameliorates cerebral blood flow and promotes microcirculation and collateral circulation of ischemic-induced stroke $[28,95]$. HBO therapy shows a greater positive effect than normobaric oxygen in increasing cerebral blood flow and prompting cerebral metabolism with severe traumatic brain injury patients [96]. In recent 
years, the researchers are more interested in the effect of HBO on molecular mechanisms of cerebral metabolism. EAA, such as glutamate, is the excitatory neurotransmitter of the central nervous system. Excessive release of EAA plays an extremely important role in ischemiareperfusion injury, activating the corresponding receptor and producing excitotoxicity. Gao-Yu etal. [97] demonstrated that permanent MCAO of male rabbits contributes to increased lactate and EAA, as well as decreased glucose, and further confirmed that HBO preconditioning could stabilize the glucose level and attenuate glutamate. A similar result is also shown in the experiment of Yang et al. [39]. These studies manifest that HBO therapy may inhibit excessive release of EAA, which is induced by ischemia-reperfusion, and reduce the neurotoxicity levels as well as regulate brain metabolism.

\section{Time Window of HBO Therapy}

To date, the therapeutic time window of HBO treatment for AIS still has no uniform standard. It is generally acknowledged that HBO interventional therapy is more efficient the sooner it is applied. A previous finding [98] suggests that the ideal timing of HBO therapy is the first $3 \mathrm{~h}$ in the post-ischemic stroke, and it may also be effective within $6 \mathrm{~h}$. Intermittent air breaks during HBO treatment is associated with reduced pulmonary and central nervous system toxicity [99]. Wang et al. [100] found that the time window of HBO can be delayed $12 \mathrm{~h}$ after the onset of ischemic injury since the anatomic structure and metabolism of neonatal are quite different from the senior. Yin and Zhang [101] demonstrated that delayed and multiple HBO treatment for MCAO models can significantly decrease the infarct ratio, ameliorate neurological deficits and expand the therapeutic window. Mu et al. [102] further explain that delayed daily HBO therapy stimulate cell proliferation and generate neuroprotective effects via stabilizing the cAMP responsive element binding protein pathway. Based on the knowledge from some preclinical and clinical studies, HBO therapy has recently been shown to be effective when started 2-5 days after ischemic stroke onset [52,77], or even in the chronic phase [20]. These studies provide references, as well as directions, for further studies of the mechanisms and clinical applications of HBO treatment.

\section{Conclusion}

There is no definitive proof for the efficacy of HBO treatment in AIS. However, as a promising nondrug and noninvasive treatment, HBO is still used in basic research and clinical studies of brain ischemia, especially with the extensive application of imaging technology, such as neuroimaging facilities (CT, SPECT and MRI), which provides an opportunity for early diagnosis and timely HBO treatment of AIS. Furthermore, HBO combined with thrombolysis seems promising in reducing secondary hemorrhage of ischemic stroke patients [103], which is worthy of further studies.

Currently, the safety and effectiveness of HBO treatment on acute ischemic stroke remains to be further studied. Even though commonly used in clinical, HBO therapy for ischemic stroke still raises some questions. (1) The molecular mechanisms of HBO exert effects on the anti-inflammatory and anti-apoptotic response and need to be further elucidated, such as the role of reactive species in the therapeutic outcomes of HBO, and the exact signaling pathway of MMP. (2) In clinical studies, there are no explicit inclusion criteria and intervention time, there may be an inadequate sample size as well as execution, resulting in detrimental or invalid outcomes. Therefore, future studies should be strictly enforced and executed with the standards of evidence-based medicine. 
Ding et al.: Hyperbaric Oxygen Therapy in Acute Ischemic Stroke: A Review

\section{References}

1 Towfighi A, Saver JL: Stroke declines from third to fourth leading cause of death in the United States: historical perspective and challenges ahead. Stroke 2011;42:2351-2355.

2 Cardiovascular disease. World Stroke Day. http://www.who.int/cardiovascular_diseases/media/events/ stroke_day/en/ (accessed November 15, 2013).

3 Bogousslavsky J, Aarli J, Kimura J: Stroke: time for a global campaign? Cerebrovasc Dis 2003;16:111-113.

-4 Feigin VL, Lawes CM, Bennett DA, Barker-Collo SL, Parag V: Worldwide stroke incidence and early case fatality reported in 56 population-based studies: a systematic review. Lancet Neurol 2009;8:355-369.

5 Tatemichi TK, Desmond DW, Stern Y, Paik M, Sano M, Bagiella E: Cognitive impairment after stroke: frequency, patterns, and relationship to functional abilities. J Neurol Neurosurg Psychiatry 1994;57:202-207.

6 Pedersen PM, Vinter K, Olsen TS: Aphasia after stroke: type, severity and prognosis. The Copenhagen Aphasia Study. Cerebrovasc Dis 2004;17:35-43.

7 Martino R, Foley N, Bhogal S, Diamant N, Speechley M, Teasell R: Dysphagia after stroke: incidence, diagnosis, and pulmonary complications. Stroke 2005;36:2756-2763.

8 West R, Hill K, Hewison J, Knapp P, House A: Psychological disorders after stroke are an important influence on functional outcomes: a prospective cohort study. Stroke 2010;41:1723-1727.

-9 Addo J, Ayerbe L, Mohan KM, Crichton S, Sheldenkar A, Chen R, Wolfe CD, McKevitt C: Socioeconomic status and stroke: an updated review. Stroke 2012;43:1186-1191.

10 Roger VL, Go AS, Lloyd-Jones DM, Benjamin EJ, Berry JD, Borden WB, Bravata DM, Dai S, Ford ES, Fox CS, Fullerton HJ, Gillespie C, Hailpern SM, Heit JA, Howard VJ, Kissela BM, Kittner SJ, Lackland DT, Lichtman JH, Lisabeth LD, Makuc DM, Marcus GM, Marelli A, Matchar DB, Moy CS, Mozaffarian D, Mussolino ME, Nichol G, Paynter NP, Soliman EZ, Sorlie PD, Sotoodehnia N, Turan TN, Virani SS, Wong ND, Woo D, Turner MB: Heart disease and stroke statistics - 2012 update: a report from the American Heart Association. Circulation 2012; 125:e2-e220.

11 Xu G, Ma M, Liu X, Hankey GJ: Is there a stroke belt in China and why? Stroke 2013;44:1775-1783.

-12 Grysiewicz RA, Thomas K, Pandey DK: Epidemiology of ischemic and hemorrhagic stroke: incidence, prevalence, mortality, and risk factors. Neurol Clin 2008;26:871-895.

13 Janardhan V, Qureshi AI: Mechanisms of ischemic brain injury. Curr Cardiol Rep 2004;6:117-123.

14 Zivin JA: Acute stroke therapy with tissue plasminogen activator (tPA) since it was approved by the US Food and Drug Administration (FDA). Ann Neurol 2009;66:6-10.

15 Kikuchi K, Miura N, Kawahara KI, Murai Y, Morioka M, Lapchak PA, Tanaka E: Edaravone (Radicut), a free radical scavenger, is a potentially useful addition to thrombolytic therapy in patients with acute ischemic stroke. Biom Rep 2013;10:7-12.

16 Weaver LK, Hopkins RO, Chan KJ, Churchill S, Elliott CG, Clemmer TP, Orme JJ, Thomas FO, Morris AH: Hyperbaric oxygen for acute carbon monoxide poisoning. N Engl J Med 2002;347:1057-1067.

17 Roeckl-Wiedmann I, Bennett M, Kranke P: Systematic review of hyperbaric oxygen in the management of chronic wounds. Br J Surg 2005;92:24-32.

18 Bennett MH, Mitchell SJ, Young D, King D: The use of deep tables in the treatment of decompression illness: the Hyperbaric Technicians and Nurses Association 2011 Workshop. Diving Hyperb Med 2012;42:171-180.

19 Lee CH, Lee L, Yang KJ, Lin TF: Top-cited articles on hyperbaric oxygen therapy published from 2000 to 2010. Undersea Hyperb Med 2012;39:1089-1098.

-20 Efrati S, Fishlev G, Bechor Y, Volkov O, Bergan J, Kliakhandler K, Kamiager I, Gal N, Friedman M, Ben-Jacob E, Golan H: Hyperbaric oxygen induces late neuroplasticity in post stroke patients - randomized, prospective trial. PLoS One 2013;8:e53716.

-21 Bennett MH, Wasiak J, Schnabel A: Hyperbaric oxygen therapy for acute ischemic stroke. Stroke 2010;41: 185-186.

22 Undersea and Hyperbaric Medical Society: Indications for hyperbaric oxygen therapy. http://membership. uhms.org/?page=Indications (accessed November 22, 2013).

23 Thom SR: Hyperbaric oxygen: its mechanisms and efficacy. Plast Reconstr Surg 2011;127:131-141.

24 Rink C, Roy S, Khan M, Ananth P, Kuppusamy P, Sen CK, Khanna S: Oxygen-sensitive outcomes and gene expression in acute ischemic stroke. J Cereb Blood Flow Metab 2010;30:1275-1287.

25 Matchett GA, Martin RD, Zhang JH: Hyperbaric oxygen therapy and cerebral ischemia: neuroprotective mechanisms. Neurol Res 2009;31:114-121.

26 Nemoto EM, Betterman K: Basic physiology of hyperbaric oxygen in brain. Neurol Res 2007;29:116-126.

27 Veltkamp R, Siebing DA, Sun L, Heiland S, Bieber K, Marti HH, Nagel S, Schwab S, Schwaninger M: Hyperbaric oxygen reduces blood-brain barrier damage and edema after transient focal cerebral ischemia. Stroke 2005; 36:1679-1683.

28 Calvert JW, Cahill J, Zhang JH: Hyperbaric oxygen and cerebral physiology. Neurol Res 2007;29:132-141.

29 Hacke W, Kaste M, Bluhmki E, Brozman M, Davalos A, Guidetti D, Larrue V, Lees KR, Medeghri Z, Machnig T, Schneider D, von Kummer R, Wahlgren N, Toni D: Thrombolysis with alteplase 3-4.5 h after acute ischemic stroke. N Engl J Med 2008;359:1317-1329.

-30 Liao XL, Wang CX, Wang YL, Wang CJ, Zhao XQ, Zhang LQ, Liu LP, Pan YS, Wang YJ: Implementation and outcome of thrombolysis with alteplase $3-4.5 \mathrm{~h}$ after acute stroke in Chinese patients. CNS Neurosci Ther 2013;19:43-47. 
Ding et al.: Hyperbaric Oxygen Therapy in Acute Ischemic Stroke: A Review

-31 Kidd PM: Integrated brain restoration after ischemic stroke - medical management, risk factors, nutrients, and other interventions for managing inflammation and enhancing brain plasticity. Altern Med Rev 2009;14: 14-35.

32 Bhardwaj A, Alkayed NJ, Kirsch JR, Hurn PD: Mechanisms of ischemic brain damage. Curr Cardiol Rep 2003;5: 160-167.

33 Radak D, Resanovic I, Isenovic ER: Link between oxidative stress and acute brain ischemia. Angiology 2013; 10:1-11.

34 Li J, Liu W, Ding S, Xu W, Guan Y, Zhang JH, Sun X: Hyperbaric oxygen preconditioning induces tolerance against brain ischemia-reperfusion injury by upregulation of antioxidant enzymes in rats. Brain Res 2008;1210:223229.

Sjoberg F, Singer M: The medical use of oxygen: a time for critical reappraisal. J Intern Med 2013;274:505-528. Thom SR: Oxidative stress is fundamental to hyperbaric oxygen therapy. J Appl Physiol 2009;106:988-995.

-37 Metodiewa D, Koska C: Reactive oxygen species and reactive nitrogen species: relevance to cyto(neuro)toxic events and neurologic disorders. An overview. Neurotox Res 2000;1:197-233.

-38 Manzanero S, Santro T, Arumugam TV: Neuronal oxidative stress in acute ischemic stroke: sources and contribution to cell injury. Neurochem Int 2013;62:712-718.

-39 Yang ZJ, Xie Y, Bosco GM, Chen C, Camporesi EM: Hyperbaric oxygenation alleviates MCAO-induced brain injury and reduces hydroxyl radical formation and glutamate release. Eur J Appl Physiol 2010;108:513-522.

40 Xue L, Yu Q, Zhang H, Liu Y, Wang C, Wang Y: Effect of large dose hyperbaric oxygenation therapy on prognosis and oxidative stress of acute permanent cerebral ischemic stroke in rats. Neurol Res 2008;30:389-393.

41 Korkmaz A, Oter S, Sadir S, Topal T, Uysal B, Ozler M, Ay H, Akin A: Exposure time related oxidative action of hyperbaric oxygen in rat brain. Neurochem Res 2008;33:160-166.

-42 Kim CH, Choi H, Chun YS, Kim GT, Park JW, Kim MS: Hyperbaric oxygenation pretreatment induces catalase and reduces infarct size in ischemic rat myocardium. Pflugers Arch 2001;442:519-525.

43 Moro MA, Cardenas A, Hurtado O, Leza JC, Lizasoain I: Role of nitric oxide after brain ischaemia. Cell Calcium 2004;36:265-275.

44 Baynosa RC, Naig AL, Murphy PS, Fang XH, Stephenson LL, Khiabani KT, Wang WZ, Zamboni WA: The effect of hyperbaric oxygen on nitric oxide synthase activity and expression in ischemia-reperfusion injury. J Surg Res 2013;183:355-361.

45 Zhou JG, Fang YQ, Liu CY, Zhou YQ, Ji YF, Liu JC: Effect of hyperbaric oxygen on the expression of nitric oxide synthase mRNA in cortex after acute traumatic cerebral injury. Zhongguo Ying Yong Sheng Li Xue Za Zhi 2012; 28:38-41.

46 Farooqui AA, Horrocks LA, Farooqui T: Modulation of inflammation in brain: a matter of fat. J Neurochem 2007;101:577-599.

47 Correale J, Villa A: The neuroprotective role of inflammation in nervous system Injuries. J Neurol 2004;251: $1304-1316$

48 Jordan J, Segura T, Brea D, Galindo MF, Castillo J: Inflammation as therapeutic objective in stroke. Curr Pharm Des 2008;14:3549-3564.

49 Kriz J: Inflammation in ischemic brain injury: timing is important. Crit Rev Neurobiol 2006;18:145-157.

50 Badr AE, Yin W, Mychaskiw G, Zhang JH: Dual effect of HBO on cerebral infarction in MCAO rats. Am J Physiol Regul Integr Comp Physiol 2001;280:R766-R770.

51 Lou M, Eschenfelder CC, Herdegen T, Brecht S, Deuschl G: Therapeutic window for use of hyperbaric oxygenation in focal transient ischemia in rats. Stroke 2004;35:578-583.

52 Lee YS, Chio CC, Chang CP, Wang LC, Chiang PM, Niu KC, Tsai KJ: Long course hyperbaric oxygen stimulates neurogenesis and attenuates inflammation after ischemic stroke. Mediators Inflamm 2013;2013:512978.

-53 Lin KC, Niu KC, Tsai KJ, Kuo JR, Wang LC, Chio CC, Chang CP: Attenuating inflammation but stimulating both angiogenesis and neurogenesis using hyperbaric oxygen in rats with traumatic brain injury. J Trauma Acute Care Surg 2012;72:650-659.

54 Breckwoldt MO, Chen JW, Stangenberg L, Aikawa E, Rodriguez E, Qiu S, Moskowitz MA, Weissleder R: Tracking the inflammatory response in stroke in vivo by sensing the enzyme myeloperoxidase. Proc Natl Acad Sci USA 2008;105:18584-18589.

55 Miljkovic-Lolic M, Silbergleit R, Fiskum G, Rosenthal RE: Neuroprotective effects of hyperbaric oxygen treatment in experimental focal cerebral ischemia are associated with reduced brain leukocyte myeloperoxidase activity. Brain Res 2003;971:90-94.

56 Yin W, Badr AE, Mychaskiw G, Zhang JH: Down regulation of COX-2 is involved in hyperbaric oxygen treatment in a rat transient focal cerebral ischemia model. Brain Res 2002;926:165-171.

57 Jadhav V, Ostrowski RP, Tong W, Matus B, Jesunathadas R, Zhang JH: Cyclo-oxygenase-2 mediates hyperbaric oxygen preconditioning-induced neuroprotection in the mouse model of surgical brain injury. Stroke 2009; 40:3139-3142.

-58 Cheng O, Ostrowski RP, Wu B, Liu W, Chen C, Zhang JH: Cyclooxygenase-2 mediates hyperbaric oxygen preconditioning in the rat model of transient global cerebral ischemia. Stroke 2011;42:484-490.

59 Romanic AM, White RF, Arleth AJ, Ohlstein EH, Barone FC: Matrix metalloproteinase expression increases after cerebral focal ischemia in rats: inhibition of matrix metalloproteinase-9 reduces infarct size. Stroke 1998;29: $1020-1030$ 
Ding et al.: Hyperbaric Oxygen Therapy in Acute Ischemic Stroke: A Review

60 Ostrowski RP, Jadhav V, Chen W, Zhang JH: Reduced matrix metalloproteinase-9 activity and cell death after global ischemia in the brain preconditioned with hyperbaric oxygen. Acta Neurochir Suppl 2010;106:47-49.

61 Vlodavsky E, Palzur E, Soustiel JF: Hyperbaric oxygen therapy reduces neuroinflammation and expression of matrix metalloproteinase-9 in the rat model of traumatic brain injury. Neuropathol Appl Neurobiol 2006;32: 40-50.

62 Zhang Q, Gould LJ: Hyperbaric oxygen reduces matrix metalloproteinases in ischemic wounds through a redox-dependent mechanism. J Invest Dermatol 2014;134:237-246.

-63 Yin D, Zhou C, Kusaka I, Calvert JW, Parent AD, Nanda A, Zhang JH: Inhibition of apoptosis by hyperbaric oxygen in a rat focal cerebral ischemic model. J Cereb Blood Flow Metab 2003;23:855-864.

64 Broughton BRS, Reutens DC, Sobey CG: Apoptotic mechanisms after cerebral ischemia. Stroke 2009;330-339.

65 Li JS, Zhang W, Kang ZM, Ding SJ, Liu WW, Zhang JH, Guan YT, Sun XJ: Hyperbaric oxygen preconditioning reduces ischemia-reperfusion injury by inhibition of apoptosis via mitochondrial pathway in rat brain. Neuroscience 2009;159:1309-1315.

66 Calvert JW, Zhou C, Nanda A, Zhang JH: Effect of hyperbaric oxygen on apoptosis in neonatal hypoxia-ischemia rat model. J Appl Physiol 2003;95:2072-2080.

67 Zhang Q, Chang Q, Cox RA, Gong X, Gould LJ: Hyperbaric oxygen attenuates apoptosis and decreases inflammation in an ischemic wound model. J Invest Dermatol 2008;128:2102-2112.

68 Lou M, Chen Y, Ding M, Eschenfelder CC, Deuschl G: Involvement of the mitochondrial ATP-sensitive potassium channel in the neuroprotective effect of hyperbaric oxygenation after cerebral ischemia. Brain Res Bull 2006; 69:109-116.

-69 Ueng SW, Yuan LJ, Lin SS, Niu CC, Chan YS, Wang IC, Yang CY, Chen WJ: Hyperbaric oxygen treatment prevents nitric oxide-induced apoptosis in articular cartilage injury via enhancement of the expression of heat shock protein 70. J Orthop Res 2013;31:376-384.

70 Adams JM, Difazio LT, Rolandelli RH, Lujan JJ, Hasko G, Csoka B, Selmeczy Z, Nemeth ZH: HIF-1: A key mediator in hypoxia. Acta Physiol Hung 2009;96:19-28.

-71 Fan X, Heijnen CJ, van der Kooij MA, Groenendaal F, van Bel F: The role and regulation of hypoxia-inducible factor-1alpha expression in brain development and neonatal hypoxic-ischemic brain injury. Brain Res Rev 2009;62:99-108.

72 Sun L, Marti HH, Veltkamp R: Hyperbaric oxygen reduces tissue hypoxia and hypoxia-inducible factor-1 alpha expression in focal cerebral ischemia. Stroke 2008;39:1000-1006.

73 Li Y, Zhou C, Calvert JW, Colohan AR, Zhang JH: Multiple effects of hyperbaric oxygen on the expression of HIF-1 alpha and apoptotic genes in a global ischemia-hypotension rat model. Exp Neurol 2005;191:198-210.

74 Peng Z, Ren P, Kang Z, Du J, Lian Q, Liu Y, Zhang JH, Sun X: Up-regulated HIF-1alpha is involved in the hypoxic tolerance induced by hyperbaric oxygen preconditioning. Brain Res 2008;1212:71-78.

75 Zhang XG, Jiang ZL, Wang GH, Li YC, Wang Y, Li X, Shen HM: Therapeutic efficacy of hyperbaric oxygen on traumatic brain injury in the rat and the underlying mechanisms. Zhongguo Ying Yong Sheng Li Xue Za Zhi 2012; 28:42-46.

76 Tai PA, Chang CK, Niu KC, Lin MT, Chiu WT, Lin CM: Attenuating experimental spinal cord injury by hyperbaric oxygen: stimulating production of vasculoendothelial and glial cell line-derived neurotrophic growth factors and interleukin-10. J Neurotrauma 2010;27:1121-1127.

77 Chen CH, Chen SY, Wang V, Chen CC, Wang KC, Chen CH, Liu YC, Lu KC, Yip PK, Ma WY, Liu CC: Effects of repetitive hyperbaric oxygen treatment in patients with acute cerebral infarction: a pilot study. ScientificWorldJournal 2012;2012:694703.

-78 Lin SS, Ueng SW, Niu CC, Yuan LJ, Yang CY, Chen WJ, Lee MS, Chen JK: Hyperbaric oxygen promotes osteogenic differentiation of bone marrow stromal cells by regulating Wnt3a/beta-catenin signaling: an in vitro and in vivo study. Stem Cell Res 2014;12:260-274.

79 Baraniak PR, McDevitt TC: Stem cell paracrine actions and tissue regeneration. Regen Med 2010;5:121-143.

-80 Xin H, Yang G: Effect of transplantation of bone marrow mesenchymal stem cells on the expression of nerve growth factor and brain-derived neurotrophic factor in rats after sciatic nerve crush injury. Human Health and Biomedical Engineering (HHBE), 2011 International Conference, Jilin, 2011, pp 1327-1330. Sofroniew MV, Vinters HV: Astrocytes: biology and pathology. Acta Neuropathol 2010;119:7-35. Kettenmann H, Hanisch UK, Noda M, Verkhratsky A: Physiology of microglia. Physiol Rev 2011;91:461-553. Wang RY, Chang HC, Chen CH, Tsai YW, Yang YR: Effects of hyperbaric oxygenation on oxidative stress in acute transient focal cerebral ischemic rats. Eur J Appl Physiol 2012;112:215-221.

-84 Lim SW, Wang CC, Wang YH, Chio CC, Niu KC, Kuo JR: Microglial activation induced by traumatic brain injury is suppressed by postinjury treatment with hyperbaric oxygen therapy. J Surg Res 2013;184:1076-1084.

-85 Wang XL, Yang YJ, Wang QH, Yu XH, Xie M, Liu CT, Wang X: Effect of hyperbaric oxygen therapy administered at different time on white matter damage following hypoxic-ischemic brain damage in neonatal rats. Zhongguo Dang Dai Er Ke Za Zhi 2007; 9:308-312.

-86 Gunther A, Kuppers-Tiedt L, Schneider PM, Kunert I, Berrouschot J, Schneider D, Rossner S: Reduced infarct volume and differential effects on glial cell activation after hyperbaric oxygen treatment in rat permanent focal cerebral ischaemia. Eur J Neurosci 2005;21:3189-3194.

87 Vila JF, Balcarce PE, Abiusi GR, Dominguez RO, Pisarello JB: Improvement in motor and cognitive impairment after hyperbaric oxygen therapy in a selected group of patients with cerebrovascular disease: a prospective single-blind controlled trial. Undersea Hyperb Med 2005;32:341-349. 
88 Tapeantong T, Poungvarin N: Delayed encephalopathy and cognitive sequelae after acute carbon monoxide poisoning: report of a case and review of the literature. J Med Assoc Thai 2009;92:1374-1379.

89 Xing J, Wang YJ, Li YR: Clinical study on acupuncture combined with hyperbaric oxygenation for improving balance function of cerebral infarction. Zhongguo Zhen Jiu 2007;27:12-14.

90 Lacey DJ, Stolfi A, Pilati LE: Effects of hyperbaric oxygen on motor function in children with cerebral palsy. Ann Neurol 2012;72:695-703.

-91 Yan WJ, Dong HL, Xiong LZ: The protective roles of autophagy in ischemic preconditioning. Acta Pharmacol Sin 2013;34:636-643.

92 Luo CL, Li BX, Li QQ, Chen XP, Sun YX, Bao HJ, Dai DK, Shen YW, Xu HF, Ni H, Wan L, Qin ZH, Tao LY, Zhao ZQ: Autophagy is involved in traumatic brain injury-induced cell death and contributes to functional outcome deficits in mice. Neuroscience 2011;184:54-63.

-93 Deb P, Sharma S, Hassan KM: Pathophysiologic mechanisms of acute ischemic stroke: an overview with emphasis on therapeutic significance beyond thrombolysis. Pathophysiology 2010;17:197-218.

94 Xu F, Liu P, Pascual JM, Xiao G, Lu H: Effect of hypoxia and hyperoxia on cerebral blood flow, blood oxygenation, and oxidative metabolism. J Cereb Blood Flow Metab 2012;32:1909-1918.

-95 Lin S, Liu J, Xin P, Fang Y, Zhang Z, Zhou K: Effect of hyperbaric oxygen on cerebral microcirculation and tissue cells in animals with cerebral ischemic injury. Space Med Med Eng (Beijing) 1998;11:338-342.

96 Rockswold SB, Rockswold GL, Zaun DA, Zhang X, Cerra CE, Bergman TA, Liu J: A prospective, randomized clinical trial to compare the effect of hyperbaric to normobaric hyperoxia on cerebral metabolism, intracranial pressure, and oxygen toxicity in severe traumatic brain injury. J Neurosurg 2010;112:1080-1094.

97 Gao-Yu C, Cong-Yina D, Li-Jun Z, Fei L, Hua F: Effects of hyperbaric oxygen preconditioning on energy metabolism and glutamate level in the peri-infarct area following permanent MCAO. Undersea Hyperb Med 2011; 38:91-99.

-98 McCormick JG, Houle TT, Saltzman HA, Whaley RC, Roy RC: Treatment of acute stroke with hyperbaric oxygen: time window for efficacy. Undersea Hyperb Med 2011;38:321-334.

99 Chavko M, McCarron RM: Extension of brain tolerance to hyperbaric $\mathrm{O}_{2}$ by intermittent air breaks is related to the time of CBF increase. Brain Res 2006;1084:196-201.

100 Wang XL, Zhao YS, Yang YJ, Xie M, Yu XH: Therapeutic window of hyperbaric oxygen therapy for hypoxicischemic brain damage in newborn rats. Brain Res 2008;1222:87-94.

101 Yin D, Zhang JH: Delayed and multiple hyperbaric oxygen treatments expand therapeutic window in rat focal cerebral ischemic model. Neurocrit Care 2005;2:206-211.

$102 \mathrm{Mu}$ J, Ostrowski RP, Soejima Y, Rolland WB, Krafft PR, Tang J, Zhang JH: Delayed hyperbaric oxygen therapy induces cell proliferation through stabilization of cAMP responsive element binding protein in the rat model of MCAo-induced ischemic brain injury. Neurobiol Dis 2013;51:133-143.

103 Sun L, Zhou W, Mueller C, Sommer C, Heiland S, Bauer AT, Marti HH, Veltkamp R: Oxygen therapy reduces secondary hemorrhage after thrombolysis in thromboembolic cerebral ischemia. J Cereb Blood Flow Metab 2010;30:1651-1660. 